\title{
Characterization of active and total fungal communities in the atmosphere over the Amazon rainforest
}

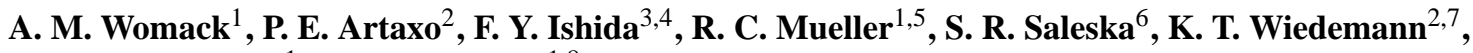 \\ B. J. M. Bohannan ${ }^{1}$, and J. L. Green ${ }^{1,8}$ \\ ${ }^{1}$ Institute of Ecology and Evolution, University of Oregon, Eugene, OR, USA \\ ${ }^{2}$ Institute of Physics, University of São Paulo, São Paulo, Brazil \\ ${ }^{3}$ Large-Scale Biosphere-Atmosphere Experiment, Instituto Nacional de Pesquisas da Amazonia, Manaus, Brazil \\ ${ }^{4}$ School of Marine and Tropical Biology, James Cook University, Cairns, Qld, Australia \\ ${ }^{5}$ Los Alamos National Laboratory, Biosciences Division, Los Alamos, NM, USA \\ ${ }^{6}$ Department of Ecology and Evolutionary Biology, University of Arizona, Tucson, AZ, USA \\ ${ }^{7}$ School of Engineering and Applied Sciences, Harvard University, Cambridge, MA, USA \\ ${ }^{8}$ Santa Fe Institute, Santa Fe, NM, USA
}

Correspondence to: A. M. Womack (womack.ann@gmail.com)

Received: 16 March 2015 - Published in Biogeosciences Discuss.: 18 May 2015

Revised: 12 October 2015 - Accepted: 17 October 2015 - Published: 6 November 2015

\begin{abstract}
Fungi are ubiquitous in the atmosphere and may play an important role in atmospheric processes. We investigated the composition and diversity of fungal communities over the Amazon rainforest canopy and compared these communities to fungal communities found in terrestrial environments. We characterized the total fungal community and the metabolically active portion of the community using highthroughput DNA and RNA sequencing and compared these data to predictions generated by a mass-balance model. We found that the total community was primarily comprised of fungi from the phylum Basidiomycota. In contrast, the active community was primarily composed of members of the phylum Ascomycota and included a high relative abundance of lichen fungi, which were not detected in the total community. The relative abundance of Basidiomycota and Ascomycota in the total and active communities was consistent with our model predictions, suggesting that this result was driven by the relative size and number of spores produced by these groups. When compared to other environments, fungal communities in the atmosphere were most similar to communities found in tropical soils and leaf surfaces. Our results demonstrate that there are significant differences in the composition of the total and active fungal communities in the atmosphere, and that lichen fungi, which have been shown to
\end{abstract}

be efficient ice nucleators, may be abundant members of active atmospheric fungal communities over the forest canopy.

\section{Introduction}

Fungi are critical to the functioning of terrestrial ecosystems and may also play an important role in the functioning of the atmosphere. Fungi are abundant and ubiquitous in the atmosphere, with an estimated global land surface emission rate of $50 \mathrm{Tg} \mathrm{yr}^{-1}$ for fungal spores alone (Elbert et al., 2007). Fungal bioaerosols are not only abundant but also affect physical and chemical processes in the atmosphere. Fungal spores, cellular fragments, and cell-free biological particles have the potential to affect precipitation by acting as ice and cloud condensation nuclei (Després et al., 2012; Morris et al., 2013; Pouleur et al., 1992; Richard et al., 1996), and metabolically active fungi sampled from the atmosphere are capable of transforming compounds known to play a major role in atmospheric chemistry, including carboxylic acids (Ariya, 2002; Côté et al., 2008; Vaïtilingom et al., 2013), formaldehyde, and hydrogen peroxide (Vaïtilingom et al., 2013).

The in situ function of airborne fungi will depend on the physiological state of fungal cells. Metabolically active vegetative cells have the potential to transform atmospheric com- 
pounds and ultimately alter atmospheric chemistry, whereas for dormant spores this metabolic capability is greatly reduced (Sussman and Douthit, 1973). The ice nucleation efficiency of fungal cells also likely depends on their physiological state; vegetative cells derived from potentially active fungi are more efficient ice nucleators than spores. Vegetative forms of Fusarium (a filamentous fungi) as well as several lichen fungi have been shown to nucleate ice at temperatures as warm as $-1{ }^{\circ} \mathrm{C}$ (Després et al., 2012; Fig. S1 in the Supplement), and ice nucleation by hyphae has been observed at $-2.5^{\circ} \mathrm{C}$. In contrast, dormant spores - particularly those with surface hydrophobins - are generally poor ice nucleators. For example, ice nucleation of rust (Puccinia) spores requires temperatures lower than $-10^{\circ} \mathrm{C}$ (Morris et al., 2013), and Cladsporium spores nucleate ice at temperatures of approximately $-28.4^{\circ} \mathrm{C}$ (Iannone et al., 2011).

Despite its importance, we know relatively little about the physiological state of fungal cells in the atmosphere. Specifically, we know little about the taxonomic composition of metabolically active airborne fungi and how this compares to the composition of the total fungal community. One way to survey the total and active communities is to measure community composition from rDNA (i.e. rRNA genes) and rRNA in ribosomes. Sequencing rDNA provides information about the total community, which includes both active and dormant individuals, whereas rRNA sequences provide information about the potentially active community, because ribosomes are more abundant in active cells than dormant cells (Prosser, 2002). This approach has been applied to study active fungal communities in soils and on decaying plant material (Baldrian et al., 2012; Barnard et al., 2013, 2015; Rajala et al., 2011) but has not been applied to fungal communities in the atmosphere.

Information about the taxonomic composition of airborne fungi that are present in different physiological states can be used to advance atmospheric science. For example, such data can be used to improve estimates of the ice nucleating capacity of fungal bioaerosols. Historically, the composition of fungal communities in the atmosphere has been measured using culture-based approaches such as the abundance of colony-forming units of specific taxa. This has led some scientists to conclude that fungal communities in the atmosphere have a low capacity for ice nucleation because taxa that appear abundant using plate counts have a low ice nucleation efficiency (Iannone et al., 2011; but see Pummer et al., 2013). These data may be misleading, as the vast majority of fungi require identification using culture-independent approaches (Borneman and Hartin, 2000). Today, cultureindependent identification of active fungal taxa sampled from the atmosphere can be used to direct selective culturing of potentially important fungi in the laboratory where their ice nucleation efficiencies and their metabolic capabilities can be further tested.

In this study, we used culture-independent approaches to measure the composition of total and active atmospheric fun- gal communities in situ and a mass-balance model to aid in the interpretation of our results. Our study system is the atmosphere above the Amazon rainforest canopy. We chose this system because fungal bioaerosols make up a substantial proportion of aerosol particulate matter over the Amazon (Elbert et al., 2007; Heald and Spracklen, 2009) and are estimated to be a dominant force responsible for cloud formation over the Amazon (Pöschl et al., 2010). We used a combined approach of DNA and RNA sequencing to address the following questions: (1) What is the composition of total airborne fungal communities? (2) What is the composition of active airborne fungal communities? (3) What likely drives differences in the composition of the total and active airborne fungal communities? (4) Is the diversity and structure of fungal communities in the atmosphere similar to that found in terrestrial environments?

\section{Methods}

\subsection{Sample collection}

Sampling was conducted on the ZF2 K34 flux tower $\left(-2.60907^{\circ} \mathrm{S},-60.20917^{\circ} \mathrm{W}, 67 \mathrm{~m}\right.$ a.s.1.) in the Reserva Biologica do Cueiras in central Amazonia, about $60 \mathrm{~km}$ NNW of Manaus, Brazil. The site is operated by the Instituto Nacional de Pesquisas da Amazonia (INPA) under the Large-Scale Biosphere-Atmosphere Experiment in Amazonia (LBA) program (Martin et al., 2010). Tower height is approximately $54 \mathrm{~m}$. Surrounding vegetation is undisturbed, mature, terra firma rainforest, with a leaf area index of 5-6 and an average canopy height of $30 \mathrm{~m}$. Samples were collected at the end of dry season over 4 days, 8-11 December 2010, from a height of $48 \mathrm{~m}$ above the forest floor. Environmental conditions during the 4-day sampling period were typical for the location in early December with partial clouds and temperatures ranging from approximately 28.5 to $32.1^{\circ} \mathrm{C}$. Heavy rain and thunderstorms occurred on 12 August and 12 September. Aerosol samples were collected using SKC Biosamplers (BioSampler SKC Inc.). Samplers were filled with $20 \mathrm{~mL}$ of a water-based preservation solution (LifeGuard Soil Preservation Solution, MO BIO Laboratories, Inc) to prevent DNase and RNase activity and maintain cells in stasis to allow accurate community profiling of the total and active fungal community. Twelve impingers were operated at $12.5 \mathrm{~L} \mathrm{~min}^{-1}$ from approximately 9 a.m. -4 p.m. local time each day. At the end of each day, the sampling liquid from all impingers was pooled and stored at $-20^{\circ} \mathrm{C}$. Impingers were cleaned each day by rinsing in $70 \%$ ethanol followed by sterilization using a portable pressure cooker.

\subsection{Nucleic acid isolation and cDNA synthesis}

Samples were transported on ice to the University of Oregon where the liquid sample from each day was separated into two aliquots, one to be used for DNA extraction and the 
other for RNA extraction. The divided samples were filtered through sterile, individually wrapped, $0.22 \mu \mathrm{m}$ cellulose nitrate filters (Nalgene Analytical Test Filter Funnels, Thermo Fisher Scientific). DNA was extracted from filters using the MO BIO PowerWater DNA Isolation Kit according to the manufacturer's instructions with a $100 \mu \mathrm{L}$ elution volume. RNA was extracted from filters using the MO BIO PowerWater RNA Isolation Kit with the following modifications. The DNase steps included in the kit were omitted. RNA was eluted in $50 \mu \mathrm{L}$. The extracted RNA was treated with DNase I (RNase-free; Fermentas International, Inc) according to the manufacturer's instructions. DNase reactions were cleaned (Zymo Research Clean and Concentrate-5) and eluted into $50 \mu \mathrm{L}$. cDNA was synthesized from the total RNA extract using the SuperScript II First-Strand Synthesis System (Invitrogen, Life Technologies Corporation) with random hexamers. All RNA was converted into cDNA in six synthesis reactions and one reverse transcriptase negative control reaction. Three field blanks were generated by filtering unused LifeGuard Solution through new, sterile filters. Blanks were processed in parallel to the RNA and DNA samples including extraction, PCR amplification, and library preparation. Following library preparation, blank samples were visualized on an agarose gel and no visible bands were observed.

\subsection{Library preparation and sequencing}

To increase the concentration of cDNA to levels required for sequencing, we used multiple displacement amplification (GenomiPhi V2, GE Healthcare) according to the protocol described in Gilbert et al. (2010) including second-stand synthesis, amplification, and de-branching of amplification products. The fully de-branched products were sheared by sonication (24 cycles, $30 \mathrm{~s}$ each) using the Bioruptor sonication system (Diagenode). cDNA fragments were endrepaired (End-It DNA End-Repair Kit, Epicentre Biotechnologies), cleaned and concentrated (Zymo Research Clean and Concentrate-5) and eluted in $40 \mu \mathrm{L}$. A-overhangs were added to the end-repaired fragments using Klenow exo(-) (Epicentre Biotechnologies) in a $50 \mu \mathrm{L}$ reaction. Reaction products were cleaned and concentrated (Zymo Research Clean and Concentrate-5). Standard paired-end, barcoded Illumina adaptors (Table S1 in the Supplement) were ligated to the fragments using T4 ligase (Fermantas). Reaction products were cleaned and concentrated (Zymo Research Clean and Concentrate-5) and eluted in $12 \mu \mathrm{L}$. To enrich fragments with ligated adaptors, PCR amplification was performed using primers containing the flowcell adaptor and complementary to the Illumina sequencing primer (Table 1 ). PCR reactions were performed using Phusion DNA polymerase (New England Biolabs) with $12 \mu \mathrm{L}$ template, $10 \mu \mathrm{L} 5 \times \mathrm{HF}$ buffer, $1 \mu \mathrm{L} 10 \mathrm{mM}$ dNTPs, $2 \mu \mathrm{L} 10 \mathrm{mM}$ primer mix, $0,5 \mu \mathrm{L}$ enzyme and $25.5 \mu \mathrm{L}$ water for a final reaction volume of $50 \mu \mathrm{L}$. PCR cycling conditions were as follows: $30 \mathrm{~s}$ denaturation at $98^{\circ} \mathrm{C}$ followed by 18 cycles of $98^{\circ} \mathrm{C}$ for $30 \mathrm{~s}, 65^{\circ} \mathrm{C}$ for
$30 \mathrm{~s}$ and $72^{\circ} \mathrm{C}$ for $30 \mathrm{~s}$ following by a final extension at $72^{\circ} \mathrm{C}$ for $5 \mathrm{~min}$. PCR products were size fractionated by gel electrophoresis $(2.5 \%$, low-melt agarose). Products in the range of 150-500 bp were excised, and DNA from the excised gel pieces was extracted (QiagenMinElute Gel Extraction) and eluted into $20 \mu \mathrm{L}$. DNA was quantitated using a Qubit 2.0 Fluorometer (Invitrogen, Life Technologies Corporation) and combined in equal molar concentrations. Shotgun metatranscriptome libraries were sequenced (150 base pairs, paired-end) on the Illumina HiSeq 2000 (Illumina, Inc.) platform at the University of Oregon Genomics Core Facility. LSU rDNA amplicons were sequenced (250 base pairs, paired-end) on the Illumina MiSeq platform at the Dana-Farber Cancer Institute Molecular Biology Core.

The D1-D2 region of the large subunit (LSU) rRNA gene was targeted using PCR with the primers LROR (5'-ACCCGCTGAACTTAAGC$\left.3^{\prime}\right)$ and LR3 (5'-CCGTGTTTCAAGACGGG-3') (http://sites.biology.duke.edu/fungi/mycolab/primers.htm). LSU amplicon libraries were prepared using a two-stage PCR procedure as described in (Kembel and Mueller, 2014) using unique combinatorial barcodes (Gloor et al., 2010) to identify samples (Table S2).

\subsection{Sequence pre-processing}

\subsubsection{Metatranscriptome}

Overlapping paired end reads were aligned and joined using fastq-join (https://code.google.com/p/ea-utils/wiki/ FastqJoin). Joined reads and non-overlapping single-end reads were trimmed and filtered using PrinSeq (Schmieder and Edwards, 2011). Sequences $<75 \mathrm{bp}$, > $2 \% \mathrm{Ns}$, and/or mean quality score $<20$ were removed. Sequence artifacts defined as exact duplicates with $>5,000$ sequences were removed. Sequences in the Dec. 10 sample were primarily artifacts, so this metatranscriptome sample was excluded from further analysis. Putative rRNAs in the remaining sequences were identified using SortMeRNA (Kopylova et al., 2012) with the non-redundant version of the following databases: rfam 5.8S (version 11.0; Burge et al., 2013); Unite (November 2011 version; Kõljalg et al., 2013), and Silva 18S and Silva 28S (Release 115; Quast et al., 2013). Of 5165185 quality-filtered reads, 1915994 with an average length of $137.5 \mathrm{bp}$ were identified as putative rRNAs (Table S3).

\subsubsection{LSU amplicons}

Forward and reverse barcodes were combined to make a $12 \mathrm{bp}$ barcode on the forward read. Only forward reads derived from the LR3 region were used for analysis. This region has been shown to have high species-level resolution even with short read lengths (Liu et al., 2012). 


\subsubsection{Multi-environment sequences}

LSU sequences from four soil studies (Barnard et al., 2013; Kerekes et al., 2013; Penton et al., 2013, 2014) and one phyllosphere study (Kembel and Mueller, 2014) were compared to air samples collected for this study (Table S4). Raw sequence data and associated metadata were downloaded from publicly available databases. $12 \mathrm{bp}$ barcodes were added to all sequences to identify each sample in downstream analysis.

\subsection{LSU amplicon and metatranscriptome sequence processing}

All sequences were processed in QIIME version $1.7(\mathrm{Ca}-$ poraso et al., 2010). Briefly, libraries were individually demultiplexed and filtered for quality. Sequences with an average quality score less than 20 , shorter than $150 \mathrm{bp}$ and with greater than two primer mismatches were discarded. The same parameters were used across all samples except the metatranscriptome rRNAs were a size cut off of greater than 75 bp was used. In order to decrease computation time, sequences from Kembel and Mueller (2014) and Penton et al. (2014) were randomly subsampled to 25 and $60 \%$ of the total number of sequences, respectively. Sequences were clustered into operational taxonomic units (OTUs) at $97 \%$ sequence similarity using closed reference BLAST (Altschul et al., 1990) against the Ribosomal Database Project (RDP) Fungal LSU training set 1 (Cole et al., 2014). The taxonomy assigned to each OTU was that of the most similar representative in the RDP database.

Following sequence processing and quality filtering, a total of 55414 amplicon and 1915994 metatranscriptome LSU sequences generated for this study and 1577458 LSU sequences from soil and phyllosphere studies were retained (Table S3). For analyses using only samples from this study, the data were rarefied to 5300 sequences per sample. For analyses that compare samples in this study to samples from other studies, the data were rarefied to 500 sequences per sample.

\subsection{Statistical analyses and data availability}

All statistical analyses were conducted in R ( $\mathrm{R}$ Core Team, 2014) primarily using the vegan (Oksanen et al., 2013) package for ecological statistics and the ggplot2 (Wickham, 2009) package for visualizations.

Sequence files and metadata have been deposited in Figshare (http://dx.doi.org/10.6084/m9.figshare.1335851). Data from other studies used for cross environment analyses are available using the databases and identifiers referenced in the respective manuscripts.

\subsection{Mass-balance model}

We use a global, well-mixed, one-box material-balance model to predict the relative abundances of fungal cells measured as gene copies sampled in the active and total portions of atmospheric bioaerosols. Model description and details are available in Appendix A.

\section{Results and discussion}

\subsection{Basidiomycota dominate total airborne fungal communities}

Measurements of airborne fungi using culture-based methods such as quantifying spore and colony-forming unit counts have been conducted for centuries (Després et al., 2012). In comparison, there have been few cultureindependent studies of the fungal composition of atmospheric samples (e.g. Boreson et al., 2004; Bowers et al., 2013; Fierer et al., 2008; Fröhlich-Nowoisky et al., 2009, 2012; Pashley et al., 2012; Yamamoto et al., 2012). Using a culture-independent approach, we found the composition of total airborne fungal communities primarily included taxa belonging to the phyla Ascomycota and Basidiomycota (Fig. 1). This result is similar to what is observed in environments on the Earth's surface (James et al., 2006) and what has been reported in other studies of fungi in the atmosphere (Bowers et al., 2013; Fröhlich-Nowoisky et al., 2009, 2012; Yamamoto et al., 2012).

Basidiomycota dominated the total airborne community in our air samples (mean relative abundance $=90.2 \pm 6.9 \%$; Fig. 1). Within the phylum Basidiomycota, Agaricomycetes were the most abundant class in our samples. Agaricomycetes have been previously detected in air samples (Fröhlich-Nowoisky et al., 2012; Woo et al., 2013; Yamamoto et al., 2012) and are common in tropical soils (Tedersoo et al., 2014) and leaf surfaces (Kembel and Mueller, 2014). Within the Agaricomycetes, the most abundant order was the Polyporales $($ mean $=55.7 \pm 2.3 \%)$. Polyporales have been detected in culture-independent studies of urban aerosols (Yamamoto et al., 2012) and culturable representatives have been isolated from cloud water (Amato et al., 2007). At the genus level, there were several taxa detected in the total community with ice nucleation activity including Acremonium, Cladosporium, Fusarium, and Rhizopus (Table S4).

The presence of Agaricomycetes may have implications for atmospheric processes. Ice nucleation efficiency within the Agaricomycetes is variable, with some taxa capable of nucleating ice at temperatures as warm as $-17^{\circ} \mathrm{C}$ (Haga et al., 2014; Fig. S1). These temperatures are warmer than what has been measured for Penicillium spores (Iannone et al., 2011) although not as warm as what has been measured for other biological particles including other spore types (Morris 


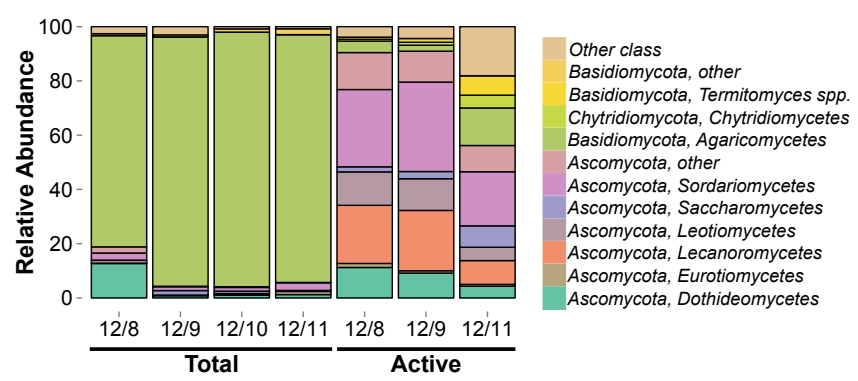

Figure 1. Basidiomycota dominate the total fungal community (mean relative abundance $=90.2 \pm 6.9 \%$ ). Bars are colored according to class-level taxonomic assignments. Taxonomy was assigned to representative sequences from each OTU.

et al., 2013), suspensions of Fusarium cultures (containing spores and hyphae; Pouleur et al., 1992), and lichen fungi (Després et al., 2012). Despite the low ice nucleation efficiency of some taxa in this group, given the high abundance of Agaricomycetes over the forest canopy, this group could still have a significant impact on cloud formation and precipitation in the tropics.

The patterns we report reflect a snapshot in space and time. As in other environmental systems, the composition of total fungal communities in the atmosphere will vary across different spatial and temporal scales. Research has shown, for example, that concentrations of fungal spores in the atmosphere vary diurnally and seasonally (Ingold, 1971). This variation is driven by complex interactions between fungal dispersal mechanisms and environmental conditions, particularly moisture and wind speed. (Lacey, 1996). Our samples were collected during the day, and spores released by mechanical disturbances often peak in abundance in the air during midday when wind speeds are highest (Lacey, 1996). Taxa that require dry conditions for dispersal also tend to release spores during the day, and taxa that require high relative humidity, including many Basidiomycota, tend to release spores at night when humidity is highest (Elbert et al., 2007; Lacey, 1996). In addition to humidity, precipitation events can also affect the dispersal of fungi. Overall concentrations of spores have been shown to increase in the atmosphere due to convective instability preceding thunderstorms (Burch and Levetin, 2002), and Ascomycota concentrations increase during and immediately after rainstorms (Elbert et al., 2007).

\subsection{Ascomycota dominate active airborne fungal communities}

The composition of total and active fungal communities over the Amazon rainforest canopy significantly differed (ADONIS, $R^{2}=0.342, p=0.029$ ). The active community in the atmosphere over the forest canopy was dominated by Ascomycota (mean relative abundance $=80.4 \pm 20 \%$; Fig. 1). Basidiomycota comprised a smaller fraction of the sampled genes $($ mean $=7.3 \pm 6.8 \%$ ) with the remainder of identi- fied sequences belonging to the phyla Chytridiomycota and Glomeromycota. This result makes sense in light of the natural histories of many of the Ascomycota, which have singlecelled or filamentous vegetative growth forms that are small enough to become aerosolized, whereas many of the Basidiomycota are too large to be easily aerosolized (Moore et al., 2011) other than in the form of metabolically inactive spores.

Similar to the total community, we expect the compositions of active fungal communities in the atmosphere likely vary over different timescales. For example, had we sampled at night rather than during the day we may have observed a higher relative abundance of Basidiomycota in the active community. This could be due to an increase in the concentration of basidiospores combined with a decrease in vegetative Ascomycota at night because basidiospores are abundant in the Amazon atmosphere at night (Elbert et al., 2007) and the detection of ribosomes within spores could lead to an increase in the observed relative abundance of Basidiomycota in the active community. We would also expect the relative abundance of Ascomycota to decrease at night when wind speeds typically decrease, particularly considering that many vegetative Ascomycota fragments are passively dispersed by wind and convection (as opposed to active mechanisms many fungi use to disperse spores). However, these patterns will depend on the relative abilities of spores (Gilbert and Reynolds, 2005) and fragments to disperse beyond the understory as well as the residence times of air parcels below and within the canopy. It will be fruitful for future studies to dynamically sample both above and below the canopy to elucidate the mechanisms driving temporal variation in fungal communities in the atmosphere.

The most abundant classes of Ascomycota detected were Sordariomycetes $($ mean $=27.1 \pm 6.6 \%)$ and Lecanoromycetes $($ mean $=17.5 \pm 7.6 \%)$. Sordariomycetes have been previously detected in culture-independent air samples (Fröhlich-Nowoisky et al., 2009, 2012; Yamamoto et al., 2012) and have been shown to be abundant on tropical tree leaves (Kembel and Mueller, 2014) and tropical soils (Peay et al., 2013). In most ecosystems, Sordariomycetes are endophytes, pathogens, and saprotophs (Zhang et al., 2007). Xylariales, which includes both endophytes and plant pathogens (Zhang et al., 2007), was the most abundant order within the Sordariomycetes in our samples. Several genera with known ice nucleation capability were detected in the active community including Agaricus, Amanita, Aspergillus, Boletus, Lepsita, Mortierella Puccinia, Rhizopus, and the lichen fungus Cladonia (Table S4). Below we focus our discussion on the class Lecanoromycetes, an understudied but potentially important group of fungi in the atmosphere.

Lecanoromycetes were the second most abundant class of Ascomycota detected over the rainforest canopy. This group has been detected in other culture-independent studies of fungi in the atmosphere (Fröhlich-Nowoisky et al., 2012; Yamamoto et al., 2012). The Lecanoromycetes contain $90 \%$ of the lichen-associated fungi (Miadlikowska et al., 
2007). Lichens are a symbiosis between a fungus and a photosynthetic partner such as eukaryotic algae or cyanobacteria. Lichens are known to be hardy and may be particularly well-adapted for long distance transport and metabolic activity in the atmosphere. Lichens are often the dominant life forms in environments that have conditions similar to those found in the atmosphere, including low water (Kranner et al., 2008) and nutrient availability, wide temperature variations, and high UV irradiance (e.g. Solhaug et al., 2003; Onofri et al., 2004).

Another notable trait of lichens is their efficient ice nucleation capacity. Although there have been no investigations specifically on the most abundant lichen species detected in this study, Physcia stellaris $($ mean $=8.3 \pm 3.8 \%$ ) and Rinodina milvina $($ mean $=4.8 \pm 3.4 \%)$, there have been multiple studies of the ice nucleation efficiency of many other lichen fungi species. Ice nucleation activity of lichens has been measured at temperatures warmer than $-8^{\circ} \mathrm{C}$, including 13 of 15 taxa tested by Henderson-Begg and colleagues (Henderson-Begg et al., 2009) and 9 of 15 taxa tested by Kieft (Kieft, 1988). These studies have demonstrated that lichens are among the most efficient biological ice nucleators. Therefore, their presence in the atmosphere may have a significant impact on cloud formation and precipitation. This ice nucleation capacity may also enable lichens to control the extent of their dispersal through the atmosphere. It is possible that lichens achieve this by nucleating ice formation, which leads to precipitation and ultimately deposition. This phenomenon has been shown to occur in some phytopathogenic bacteria (Morris et al., 2008, 2010) and may occur in fungi as well (Morris et al., 2013).

\subsection{Dominance of Basidiomycota in total communities and Ascomycota in active communities is consistent with mass-balance predictions}

Our mass balance model (Appendix A) predicted Basidiomycota would dominate the total community because they produce orders of magnitude more spores and have smaller aerodynamic diameters compared to Ascomycota. Consistent with this prediction, the total airborne community was dominated by Basidiomycota in our air samples (mean relative abundance $=90.2 \pm 6.9 \%$; Fig. 1 ). There have been some empirical studies reporting the opposite pattern, with a higher relative abundance of Ascomycota compared to Basidiomycota (Bowers et al., 2013; Fierer et al., 2008; Pashley et al., 2012). There has been one study focused on airborne fungal communities in the Amazon Basin (FröhlichNowoisky et al., 2012). Although the site of this study was the atmosphere above a rural pasture (versus a tropical rainforest, as in our study) these investigators also found that $\mathrm{Ba}$ sidiomycota dominate airborne fungal communities.

Our mass-balance model explains the differences in composition between the total and active air communities. However, some of the differences we observed may be partially attributable to the use of different approaches in characterizing the total and active communities. In this study, the total community was characterized by PCR-based amplification and sequencing of LSU genes, whereas the active community was characterized through random sequencing of all the RNA present in the samples. Shotgun metatranscriptome sequencing and PCR-based community characterization approaches each have their own biases (Hong et al., 2009; Morgan et al., 2010). Our data suggest that the selection of LSU primers led to biased results. For example, the high relative abundance of lichen fungi (class Lecanoromycetes) in the active community was unexpected because this group was not detected in the total community and has only been detected in low abundance in other PCR-based studies of fungi in the atmosphere (Fröhlich-Nowoisky et al., 2012). We tested the primer pair used in this study (LR0R-LR3) using the SILVA TestPrime tool (Klindworth et al., 2013) and found coverage of the Lecanoromycetes with this primer pair was $71.4 \%$. Within the class Lecanoromycetes, the order Teloschistales, which contains the most abundant species detected in the active community, would not have been detected with this primer pair. However, the general pattern that Ascomycota were much less abundant than Basidiomycota in the total community is not likely due to primer bias as coverage of the phylum Ascomycota by the LR0R-LR3 primer pair is $85.5 \%$ according to TestPrime. Our findings underscore the value of using a combination of PCR-based and shotgun-based sequencing approaches, particularly in environments that are understudied and where little is known about microbiome structure and function.

\subsection{Fungal air communities above the forest canopy are most similar in composition to tropical phyllosphere and soil communities}

We compared total and active fungal air communities to communities from tropical, temperate, and tundra soils and from the surfaces of tropical tree leaves. Community composition significantly differed across environment types (ADONIS, $R^{2}=0.167, p=0.001$ ), and fungal communities in the atmosphere were compositionally distinct from communities in other environments (Fig. 2). Ascomycota was the most abundant phylum across all soil and phyllosphere samples (soil mean relative abundance $=78.4 \pm 14.9 \%$, phyllosphere $=90.9 \pm 4.9 \%$ ) followed by Basidiomycota (soil mean relative abundance $=19.0 \pm 14.9 \%$, phyllosphere $=7.4 \pm 4.5 \%$; Fig. 3). We expected communities to be distinct across habitat types because environmental conditions may differ across the habitat types and select for different communities. However, in the atmosphere, dispersal and mixing of fungi from multiple habitat types may be driving the observed community composition differences instead of environmental selection.

The diversity of fungal communities in the atmosphere is within the range of diversities reported for terrestrial en- 


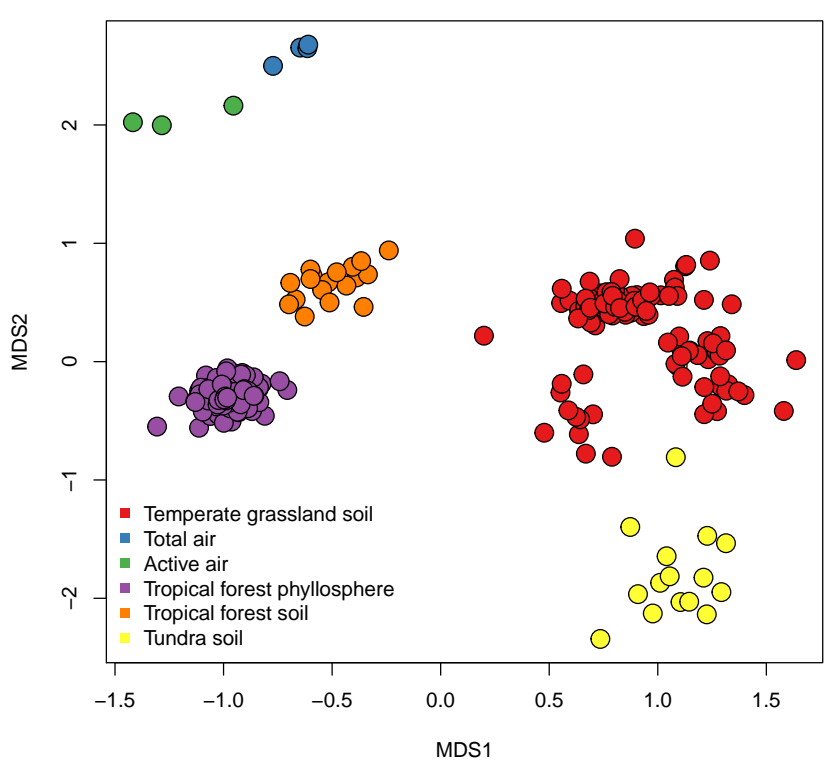

Figure 2. OTU-based community composition significantly differed across environment types (ADONIS, $R^{2}=0.167, p=0.001$ ). Total and active communities in air samples (upper left) clustered together and separate from other environments indicating that these communities are distinct from communities found in soils and on leaf surfaces. Sørensen similarities are depicted, ordinated via NMDS.

vironments, including those of tropical leaf surfaces, tropical soils, temperate grassland soils, and tundra soils. Overall taxonomic richness, defined as the number of OTUs, significantly varied among environment types (ANOVA, $F(5237)=66.89, p<0.001$; Fig. S2). Tukey's HSD post-hoc comparisons indicated that the richness of air communities, both total and active, was greater than tundra soil communities and did not significantly differ from temperate grassland soil communities. In general, air communities were less diverse than tropical forest phyllosphere and soil communities with the exception of tropical forest soils and active air communities, which did not significantly differ. Similar patterns have been observed in soil communities where taxonomic richness in arctic soils was significantly lower than soils from temperate and tropical ecosystems (Fierer et al., 2012).

Total air communities were most similar to tropical phyllosphere communities (mean Sørensen similarity $=0.015 \pm 0.009$; Tukey's HSD, $p<0.001$ ) and active air communities were most similar to tropical soil communities (mean Sørensen similarity $=0.010 \pm 0.007$, Tukey's HSD, $p<0.001$; Fig. S3). This suggestion makes sense since fungal spores and hyphae are relatively large aerosol particles with short residence times in the atmosphere, limiting opportunities for long-distance dispersal. While these results are suggestive, detailed information is lacking regarding the potential influence of terrestrial source environments and their role in structuring airborne fungal communities.

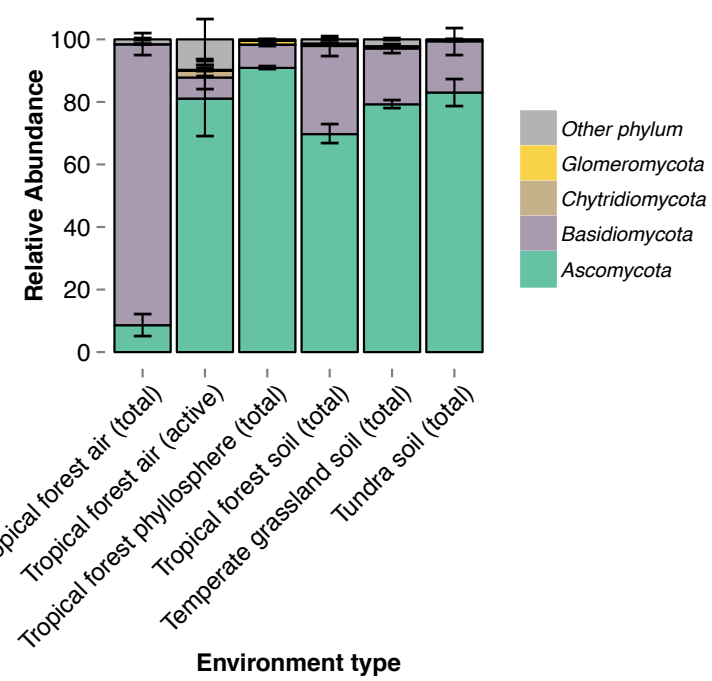

Figure 3. Relative abundances of fungal phyla across environment types. The active atmospheric fungal community over the Amazon rainforest was more similar in phylum-level composition to fungal communities found in tropical soils and on plant leaves than was the total community. Error bar represent standard deviations.

\section{Conclusions}

Fungi in the atmosphere play an important role in atmospheric processes including precipitation development through ice nucleation. This is of particular significance in the atmosphere over the Amazon rainforest canopy where fungi constitute a large fraction of the total aerosol content (Elbert et al., 2007; Heald and Spracklen, 2009) and precipitation is aerosol-limited (Pöschl et al., 2010). Our study represents the first culture-independent survey of fungal communities over the Amazon rainforest canopy. It is also the first to measure metabolically active microbial communities in the atmosphere using an RNA-based approach. Using this RNA-based approach, we found evidence for the presence of potentially active fungi in the atmosphere, including lichen fungi (class Lecanonomycetes) and the following genera: Agaricus; Amanita; Aspergillus; Boletus; Cladonia; Lepsita; Mortierella; Puccinia; and Rhizopus. While an understanding of the structure of fungal communities in the atmosphere is beginning to emerge, studies on the function of these communities have lagged behind. We suggest that future research focus on understanding the functional capacity of airborne microbes with traits particularly well-suited for survival and metabolic activity in extreme environments. As with any environment, understanding both the structure and function of microbial communities in the atmosphere is needed to assess their potential impact on ecosystem processes such as water and carbon cycling. This study opens the door for future investigations of the diversity and function of fungal communities in the atmosphere. 


\section{Appendix A: Mass-balance model}

We use a global, well-mixed, one-box material-balance model to explain the relative abundances of fungal cells measured as gene copies sampled in the active and total portions of atmospheric bioaerosols. By material-balance, for any taxon $i$ within a biological community, the change in time in the abundance of fungal gene copies, $N_{i}$, must be equal to the difference in source and sinks:

$\frac{\mathrm{d} N_{i}}{\mathrm{~d} t}=\sum$ sources- $\sum$ sinks.

Here we assume sources are equal to the emission of fungal gene copies from the Earth's surface into the atmosphere, $E_{i}$ (gene copies/hour). We assume sinks are equal to deposition of fungal gene copies out of the atmosphere back to the Earth's surface, $D_{i}=N_{i} k_{i}$, (gene copies/hour), where $k_{i}(1 /$ hour $)$ represents a first order deposition coefficient. We can rewrite Eq. (A2) as:

$\frac{\mathrm{d} N_{i}}{\mathrm{~d} t}=E_{i}-N_{i} k_{i}$

We expect the terms $E_{i}$ and $k_{i}$ to vary as a function of life history traits including the method of cell release into the atmosphere, the physiological state of sampled cells, and the aerodynamic diameter of fungal taxa. In this case, Eq. (A2) does not directly represent the entire airborne fungal gene copy abundance. We assume that a first order approximation of fungal bioaerosol behavior may be obtained by subdividing the particle distribution into two modes: vegetative cells, $N_{i, \text { veg }}$, and spores, $N_{i \text {,spores. We thus model fungal gene copy }}$ abundance as:

$N_{i}=N_{i, \mathrm{veg}}+N_{i, \text { spores }}$.

We can then write and solve parallel versions of Eq. (A3) for each mode. At steady state, the expected gene copy abundance taxa $i$ in each mode is:

$$
\begin{aligned}
& N_{i, \text { veg }}=\frac{E_{i, \text { veg }}}{k_{i, \text { veg }}} \\
& N_{i, \text { spore }}=\frac{E_{i, \text { spore }}}{k_{i, \text { spore }}}
\end{aligned}
$$

Our interest lies in the two most common fungal phyla sampled in the atmosphere: Ascomycota, $N_{\mathrm{A}}$, and Basidiomycota, $N_{\mathrm{B}}$. To make predictions about the expected relative abundance of gene copies in these two groups, we make informed assumptions about the relative magnitude of their respective emission and deposition rates. We begin by considering fungal spores. Although a few empirical studies have suggested that Ascomycota are more abundant than Basidiomycota in likely source environments including tropical soils (Kerekes et al., 2013) and leaf surfaces (Kembel and Mueller, 2014), Basidiomycota (e.g. Agaricomycetes, the most abundant class of Basidiomycota in our samples) produce orders of magnitude more spores per individual than Ascomycota (Elbert et al., 2007; Pringle, 2013). For this reason, we assume the emission rate of Basidiomycota spores is much greater than that of Ascomycota spores:

$E_{\mathrm{A} \text {,spores }} \ll E_{\mathrm{B} \text {,spores }}$.

Culture-based microscopy data suggest that spores of Ascomycota are typically larger than spores of Basidiomycota (Elbert et al., 2007; Ingold, 2001; Yamamoto et al., 2014). Owing to the difference in spore size, we expect deposition rate of Ascomycota spores to be greater than that of Basidiomycota spores:

$k_{\mathrm{d}, \mathrm{A}, \text { spores }}>k_{\mathrm{d}, \mathrm{B}, \text { spores }}$.

Based on these assumptions, it follows that the expected number of Ascomycota spores in the atmosphere will be less than the number of Basidiomycota spores:

$$
\frac{E_{\mathrm{A}, \text { spore }}}{k_{\mathrm{A}, \text { spore }}} \ll \frac{E_{\mathrm{B}, \text { spore }}}{k_{\mathrm{B}, \text { spore }}}
$$

or

$N_{\mathrm{A} \text {,spores }} \ll N_{\mathrm{B} \text {,spores }}$.

We next consider fungal vegetative cells. Vegetative forms of Ascomycota are generally smaller than vegetative forms of Basidiomycota (Moore et al., 2011). Many Ascomycota grow as filaments or single cells which are small enough to be aerosolized (Després et al., 2012). In contrast, many Basidiomycota grow as mushrooms, which are too large to be aerosolized (although debris from mushrooms and their mycelia can be aerosolized). Due to this difference in the vegetative forms of each group, we expect emission rate of vegetative Ascomycota to be greater than Basidiomycota:

$E_{\mathrm{A}, \text { veg }}>E_{\mathrm{B}, \text { veg }}$.

No comparative data currently exist on the relative deposition rate of vegetative cells across fungal taxa. Research has shown that at the phylum level, the aerodynamic diameter of Ascomycota is greater than that of Basidiomycota, resulting in a greater deposition rate overall for Ascomycota (Yamamoto et al., 2014). However, this work did not differentiate between vegetative cells and spores, and there is no a priori reason to assume that the deposition rate of Ascomycota vegetative cells are less than or greater to that of Basidiomycota cells. For this reason, we make the null assumption that the deposition rate of each group is equal:

$k_{\mathrm{d}, \mathrm{A}, \mathrm{veg}}=k_{\mathrm{d}, \mathrm{B}, \mathrm{veg}}$.

Based on these assumptions, we expect the number of vegetative Ascomycota genes to be greater than the number of vegetative Basidiomycota genes:

$\frac{E_{\mathrm{A}, \mathrm{veg}}}{k_{\mathrm{A}, \mathrm{veg}}}>\frac{E_{\mathrm{B}, \mathrm{veg}}}{k_{\mathrm{B}, \mathrm{veg}}}$ 
or

$N_{\mathrm{A}, \mathrm{veg}}>N_{\mathrm{B}, \mathrm{veg}}$.

Equation (A4) predicts that Ascomycota will dominate the active fungal community in the atmosphere.

Finally, we relate the abundance of Ascomycota and Basiodiomycota gene copies in their totality to ask if $N_{\mathrm{A}}<N_{\mathrm{B}}$ or $N_{\mathrm{A}} \geq N_{\mathrm{B}} . N_{\mathrm{A}}<N_{\mathrm{B}}$ if and only if:

$N_{\mathrm{A}, \mathrm{veg}}+N_{\mathrm{A}, \text { spores }}<N_{\mathrm{B}, \mathrm{veg}}+N_{\mathrm{B}, \text { spores }}$.

Rearranging terms and dividing both sides of the equation by $N_{\mathrm{B} \text {,spores }}$ yields the inequality:

$\frac{N_{\mathrm{A}, \mathrm{veg}}-N_{\mathrm{B}, \mathrm{veg}}}{N_{\mathrm{B}, \text { spores }}}+\frac{N_{\mathrm{A}, \text { spores }}}{N_{\mathrm{B}, \text { spores }}}<1$

or

$\frac{N_{\mathrm{A}, \mathrm{veg}}-N_{\mathrm{B}, \mathrm{veg}}}{N_{\mathrm{B}, \mathrm{spores}}}<1-\varepsilon$,

where $\varepsilon=\frac{N_{\mathrm{A}, \text { spores }}}{N_{\mathrm{B}, \mathrm{spores}}}$. Empirical data on the discharge of Ascomycota and Basidiomycota spores from fruiting bodies suggest that $\varepsilon \leq 0.01$ (Elbert et al., 2007). In this case $N_{\mathrm{A}}<$ $N_{\mathrm{B}}$ if and only if:

$\frac{N_{\mathrm{A}, \mathrm{veg}}-N_{\mathrm{B}, \mathrm{veg}}}{N_{\mathrm{B}, \mathrm{spores}}}<0.99$.

We expect Eq. (A5) to hold due to the likelihood that spores greatly outnumber vegetative cells in the atmosphere in both phyla. Spores can be actively discharged into the air, whereas vegetative cells are not actively propelled into the atmosphere and require aerosolization by mechanical forces like wind. Furthermore, empirical data suggest that vegetative cell fragments constitute a small fraction $(0.2-16 \%$; Green et al., 2011) of the total fungal biomass in the atmosphere. For these reasons, we predict that

$N_{\mathrm{A}}<N_{\mathrm{B}}$.
Based on the conclusions of this model, we expect Basidiomycota will dominate the total community, and Ascomycota will dominate the active community in the atmosphere. We note there are many limitations to our model. First, we model fungal gene copy abundances assuming a well-mixed atmosphere at steady state. Yet the atmosphere is a highly heterogeneous and dynamic environment; the sampled air volume was likely neither well mixed nor at steady state over the time intervals we measured. Second, we use a global model with emission and deposition as the sole input and output, whereas a local model that incorporated site-specific environmental fate and transport terms would likely provide more accurate expectations. Third, due to a paucity of data, our estimates of fungal gene abundance levels rely on assumptions about the emission and deposition rates of vegetative cells and spores across fungal taxonomic groups. Empirically derived estimates of these model parameters would significantly improve our approach. Fourth, we do not know to what extent vegetative cells and spores are associated with other particulate matter and how this affects their deposition and emission rates. Adopting an approach to empirically estimate the aerodynamic diameter of these fungal cell types across taxonomic groups would allow for improved estimates of deposition rates (Yamamoto et al., 2014). 


\section{The Supplement related to this article is available online at doi:10.5194/bg-12-6337-2015-supplement.}

Author contributions. A. M. Womack conceived and designed the experiments, analyzed the data, wrote the paper, prepared figures and/or tables, and reviewed drafts of the paper. P. E. Artaxo conceived and designed the experiments. F. Y. Ishida collected the samples and reviewed drafts of the paper. R. C. Mueller conceived and designed the experiments, reviewed drafts of the paper and contributed reagents/materials/analysis tools. S. R. Saleska conceived and designed the experiments. K. T. Wiedemann collected the samples. B. J. M. Bohannan conceived and designed the experiments, collected the samples, and reviewed drafts of the paper. J. L. Green conceived and designed the experiments, wrote the paper, reviewed drafts of the paper, and contributed reagents/materials/analysis tools.

Acknowledgements. This research was funded by the University of Oregon and the Alfred P. Sloan Foundation. We thank Jonas Frankel-Bricker for his work in preparing the LSU libraries for sequencing. We also thank members of the Green and Bohannan labs for their constructive feedback during the preparation of this manuscript.

Edited by: P. Stoy

\section{References}

Altschul, S. F., Gish, W., Miller, W., Myers, E. W. and Lipman, D. J.: Basic local alignment search tool., J. Mol. Biol., 215, 403-10, doi:10.1016/S0022-2836(05)80360-2, 1990.

Amato, P., Parazols, M., Sancelme, M., Laj, P., Mailhot, G., and Delort, A.-M.: Microorganisms isolated from the water phase of tropospheric clouds at the Puy de Dôme: major groups and growth abilities at low temperatures, FEMS Microbiol. Ecol., 59, 24254, doi:10.1111/j.1574-6941.2006.00199.x, 2007.

Ariya, P. A.: Microbiological degradation of atmospheric organic compounds, Geophys. Res. Lett., 29, 2-5, doi:10.1029/2002GL015637, 2002.

Baldrian, P., Kolařík, M., Stursová, M., Kopecký, J., Valášková, V., Větrovský, T., Zifčáková, L., Snajdr, J., Rídl, J., Vlček, C., and Voříšková, J.: Active and total microbial communities in forest soil are largely different and highly stratified during decomposition, ISME J., 6, 248-58, doi:10.1038/ismej.2011.95, 2012.

Barnard, R. L., Osborne, C., and Firestone, M. K.: Responses of soil bacterial and fungal communities to extreme desiccation and rewetting, ISME J., 7, 2229-41, doi:10.1038/ismej.2013.104, 2013.

Barnard, R. L., Osborne, C. A., and Firestone, M. K.: Changing precipitation pattern alters soil microbial community response to wet-up under a Mediterranean-type climate, ISME J., 9, 946957, doi:10.1038/ismej.2014.192, 2015.
Boreson, J., Dillner, A., and Peccia, J.: Correlating bioaerosol load with PM2.5 and PM10cf concentrations: a comparison between natural desert and urban-fringe aerosols, Atmos. Environ., 38, 6029-6041, doi:10.1016/j.atmosenv.2004.06.040, 2004.

Borneman, J. and Hartin, R. J.: PCR Primers That Amplify Fungal rRNA Genes from Environmental Samples, Appl. Environ. Microbiol., 66, 4356-4360, doi:10.1128/AEM.66.10.43564360.2000, 2000.

Bowers, R. M., Clements, N., Emerson, J. B., Wiedinmyer, C., Hannigan, M. P., and Fierer, N.: Seasonal variability in bacterial and fungal diversity of the near-surface atmosphere, Environ. Sci Technol., 47, 12097-106, doi:10.1021/es402970s, 2013.

Burge, S. W., Daub, J., Eberhardt, R., Tate, J., Barquist, L., Nawrocki, E. P., Eddy, S. R., Gardner, P. P., and Bateman, A.: Rfam 11.0: 10 years of RNA families, Nucleic Acids Res., 41, 226-232, doi:10.1093/nar/gks1005, 2013.

Burch, M. and Levetin, E.: Effects of meteorological conditions on spore plumes, Int. J. Biometeorol., 46, 107-17, doi:10.1007/s00484-002-0127-1, 2002.

Caporaso, J. G., Kuczynski, J., Stombaugh, J., Bittinger, K., Bushman, F. D., Costello, E. K., Fierer, N., Peña, A. G., Goodrich, J. K., Gordon, J. I., Huttley, G. A., Kelley, S. T., Knights, D., Koenig, J. E., Ley, R. E., Lozupone, C. A., McDonald, D., Muegge, B. D., Pirrung, M., Reeder, J., Sevinsky, J. R., Turnbaugh, P. J., Walters, W. A., Widmann, J., Yatsunenko, T., Zaneveld, J., and Knight, R.: QIIME allows analysis of highthroughput community sequencing data, Nat. Methods, 7, 335336, doi:10.1038/nmeth.f.303, 2010.

Cole, J. R., Wang, Q., Fish, J. A., Chai, B., McGarrell, D. M., Sun, Y., Brown, C. T., Porras-Alfaro, A., Kuske, C. R., and Tiedje, J. M.: Ribosomal Database Project: data and tools for high throughput rRNA analysis, Nucleic Acids Res., 42, 633642, doi:10.1093/nar/gkt1244, 2014

Côté, V., Kos, G., Mortazavi, R., and Ariya, P. A.: Microbial and "de novo" transformation of dicarboxylic acids by three airborne fungi, Sci. Total Environ., 390, 530-7, doi:10.1016/j.scitotenv.2007.10.035, 2008.

Després, V. R., Huffman, J. A., Burrows, S. M., Hoose, C., Safatov, A. S., Buryak, G., Fröhlich-Nowoisky, J., Elbert, W., Andreae, M. O., Pöschl, U., and Jaenicke, R.: Primary biological aerosol particles in the atmosphere: a review, Tellus B, 64, doi:10.3402/tellusb.v64i0.15598, 2012.

Elbert, W., Taylor, P. E., Andreae, M. O., and Pöschl, U.: Contribution of fungi to primary biogenic aerosols in the atmosphere: wet and dry discharged spores, carbohydrates, and inorganic ions, Atmos. Chem. Phys., 7, 4569-4588, doi:10.5194/acp-7-4569-2007, 2007.

Fierer, N., Liu, Z., Rodríguez-Hernández, M., Knight, R., Henn, M., and Hernandez, M. T.: Short-term temporal variability in airborne bacterial and fungal populations, Appl. Environ. Microbiol., 74, 200-7, doi:10.1128/AEM.01467-07, 2008.

Fierer, N., Leff, J. W., Adams, B. J., Nielsen, U. N., Bates, S. T., Lauber, C. L., Owens, S., Gilbert, J. a, Wall, D. H., and Caporaso, J. G.: Cross-biome metagenomic analyses of soil microbial communities and their functional attributes, P. Natl. Acad. Sci. USA, 109, 21390-5, doi:10.1073/pnas.1215210110, 2012.

Fröhlich-Nowoisky, J., Pickersgill, D. A., Després, V. R., and Pöschl, U.: High diversity of fungi in air partic- 
ulate matter, P. Natl. Acad. Sci. USA, 106, 12814-9, doi:10.1073/pnas.0811003106, 2009.

Fröhlich-Nowoisky, J., Burrows, S. M., Xie, Z., Engling, G., Solomon, P. A., Fraser, M. P., Mayol-Bracero, O. L., Artaxo, P., Begerow, D., Conrad, R., Andreae, M. O., Després, V. R., and Pöschl, U.: Biogeography in the air: fungal diversity over land and oceans, Biogeosciences, 9, 1125-1136, doi:10.5194/bg9-1125-2012, 2012.

Gilbert, G. S. and Reynolds, D. R.: Nocturnal Fungi: Airborne Spores in the Canopy and Understory of a Tropical Rain Forest, Biotropica, 37, 462-464, doi:10.1111/j.17447429.2005.00061.x, 2005.

Gilbert, J. A., Zhang, K., and Neufeld, J. D.: Handbook of Hydrocarbon and Lipid Microbiology, in Handbook of Hydrocarbon and Lipid Microbiology, edited by: Timmis, K. N., 4256-4262, Springer Berlin Heidelberg, Berlin, Heidelberg, 2010.

Gloor, G. B., Hummelen, R., Macklaim, J. M., Dickson, R. J., Fernandes, A. D., MacPhee, R., and Reid, G.: Microbiome profiling by illumina sequencing of combinatorial sequence-tagged PCR products, PLoS One, 5, e15406, doi:10.1371/journal.pone.0015406, 2010.

Green, B., Schmechel, D., and Summerbell, R.: Aerosolized fungal fragments, in Fundamentals of mold growth in indoor environments and strategies for healthy living, edited by: Adan, O. C. and Samson, R. A., 211-243, Wageningen Academic Publishers, 2011.

Haga, D. I., Burrows, S. M., Iannone, R., Wheeler, M. J., Mason, R. H., Chen, J., Polishchuk, E. A., Pöschl, U., and Bertram, A. K.: Ice nucleation by fungal spores from the classes Agaricomycetes, Ustilaginomycetes, and Eurotiomycetes, and the effect on the atmospheric transport of these spores, Atmos. Chem. Phys., 14, 8611-8630, doi:10.5194/acp-14-8611-2014, 2014.

Heald, C. L. and Spracklen, D. V.: Atmospheric budget of primary biological aerosol particles from fungal spores, Geophys. Res. Lett., 36, L09806, doi:10.1029/2009GL037493, 2009.

Henderson-Begg, S. K., Hill, T., Thyrhaug, R., Khan, M., and Moffett, B. F.: Terrestrial and airborne non-bacterial ice nuclei, Atmos. Sci. Lett., 10, 215-219, doi:10.1002/asl.241, 2009.

Hong, S., Bunge, J., Leslin, C., Jeon, S., and Epstein, S. S.: Polymerase chain reaction primers miss half of rRNA microbial diversity, ISME J., 3, 1365-73, doi:10.1038/ismej.2009.89, 2009.

Iannone, R., Chernoff, D. I., Pringle, A., Martin, S. T., and Bertram, A. K.: The ice nucleation ability of one of the most abundant types of fungal spores found in the atmosphere, Atmos. Chem. Phys., 11, 1191-1201, doi:10.5194/acp-11-1191-2011, 2011.

Ingold, C. T.: Fungal spores: Their liberation and dispersal, Oxford: Clarendon Press, 214-238, 1971.

Ingold, C. T.: Range in size and form of basidiospores and ascospores, Mycologist, 15, 165-166, doi:10.1016/S0269915X(01)80010-0, 2001.

James, T. Y., Kauff, F., Schoch, C. L., Matheny, P. B., Hofstetter, V., Cox, C. J., Celio, G., Gueidan, C., Fraker, E., Miadlikowska, J., Lumbsch, H. T., Rauhut, A., Reeb, V., Arnold, A. E., Amtoft, A., Stajich, J. E., Hosaka, K., Sung, G.-H., Johnson, D., O'Rourke, B., Crockett, M., Binder, M., Curtis, J. M., Slot, J. C., Wang, Z., Wilson, A. W., Schüssler, A., Longcore, J. E., O’Donnell, K., Mozley-Standridge, S., Porter, D., Letcher, P. M., Powell, M. J., Taylor, J. W., White, M. M., Griffith, G. W., Davies, D. R., Humber, R. A., Morton, J. B., Sugiyama, J., Rossman, A. Y.,
Rogers, J. D., Pfister, D. H., Hewitt, D., Hansen, K., Hambleton, S., Shoemaker, R. A., Kohlmeyer, J., Volkmann-Kohlmeyer, B., Spotts, R. A., Serdani, M., Crous, P. W., Hughes, K. W., Matsuura, K., Langer, E., Langer, G., Untereiner, W. A., Lücking, R., Büdel, B., Geiser, D. M., Aptroot, A., Diederich, P., Schmitt, I., Schultz, M., Yahr, R., Hibbett, D. S., Lutzoni, F., McLaughlin, D. J., Spatafora, J. W., and Vilgalys, R.: Reconstructing the early evolution of Fungi using a six-gene phylogeny, Nature, 443, 818-22, doi:10.1038/nature05110, 2006.

Kembel, S. W. and Mueller, R. C.: Plant traits and taxonomy drive host associations in tropical phyllosphere fungal communities, Botany, 92, 303-311, doi:10.1139/cjb-2013-0194, 2014.

Kerekes, J., Kaspari, M., Stevenson, B., Nilsson, R. H., Hartmann, M., Amend, A., and Bruns, T. D.: Nutrient enrichment increased species richness of leaf litter fungal assemblages in a tropical forest, Mol. Ecol., 22, 2827-38, doi:10.1111/mec.12259, 2013.

Kieft, T. L.: Ice Nucleation Activity in Lichens, Appl. Environ. Microbiol., 54, 1678-1681, 1988.

Klindworth, A., Pruesse, E., Schweer, T., Peplies, J., Quast, C., Horn, M., and Glöckner, F. O.: Evaluation of general 16S ribosomal RNA gene PCR primers for classical and next-generation sequencing-based diversity studies, Nucleic Acids Res., 41, e1, doi:10.1093/nar/gks808, 2013.

Kõljalg, U., Nilsson, R. H., Abarenkov, K., Tedersoo, L., Taylor, A. F. S., Bahram, M., Bates, S. T., Bruns, T. D., Bengtsson-Palme, J., Callaghan, T. M., Douglas, B., Drenkhan, T., Eberhardt, U., Dueñas, M., Grebenc, T., Griffith, G. W., Hartmann, M., Kirk, P. M., Kohout, P., Larsson, E., Lindahl, B. D., Lücking, R., Martín, M. P., Matheny, P. B., Nguyen, N. H., Niskanen, T., Oja, J., Peay, K. G., Peintner, U., Peterson, M., Põldmaa, K., Saag, L., Saar, I., Schüßler, A., Scott, J. A., Senés, C., Smith, M. E., Suija, A., Taylor, D. L., Telleria, M. T., Weiss, M., and Larsson, K.-H.: Towards a unified paradigm for sequence-based identification of fungi, Mol. Ecol., 22, 5271-7, doi:10.1111/mec.12481, 2013.

Kopylova, E., Noé, L., and Touzet, H.: SortMeRNA: fast and accurate filtering of ribosomal RNAs in metatranscriptomic data, Bioinformatics, 28, 3211-3217, doi:10.1093/bioinformatics/bts611, 2012.

Kranner, I., Beckett, R., Hochman, A., and Nash, T. H.: Desiccation-Tolerance in Lichens: A Review, Bryologist, 111, 576-593, doi:10.1639/0007-2745-111.4.576, 2008.

Lacey, J.: Spore dispersal - its role in ecology and disease: the British contribution to fungal aerobiology, Mycol. Res., 100, 641-660, doi:10.1016/S0953-7562(96)80194-8, 1996.

Liu, K.-L., Porras-Alfaro, A., Kuske, C. R., Eichorst, S. A., and Xie, G.: Accurate, rapid taxonomic classification of fungal largesubunit rRNA genes, Appl. Environ. Microbiol., 78, 1523-33, doi:10.1128/AEM.06826-11, 2012.

Martin, S. T., Andreae, M. O., Althausen, D., Artaxo, P., Baars, H., Borrmann, S., Chen, Q., Farmer, D. K., Guenther, A., Gunthe, S. S., Jimenez, J. L., Karl, T., Longo, K., Manzi, A., Müller, T., Pauliquevis, T., Petters, M. D., Prenni, A. J., Pöschl, U., Rizzo, L. V., Schneider, J., Smith, J. N., Swietlicki, E., Tota, J., Wang, J., Wiedensohler, A., and Zorn, S. R.: An overview of the Amazonian Aerosol Characterization Experiment 2008 (AMAZE08), Atmos. Chem. Phys., 10, 11415-11438, doi:10.5194/acp-1011415-2010, 2010.

Miadlikowska, J., Kauff, F., Hofstetter, V., Fraker, E., Grube, M., Hafellner, J., Reeb, V., Hodkinson, B. P., Kukwa, M., Luck- 
ing, R., Hestmark, G., Otalora, M. G., Rauhut, A., Budel, B., Scheidegger, C., Timdal, E., Stenroos, S., Brodo, I., Perlmutter, G. B., Ertz, D., Diederich, P., Lendemer, J. C., May, P., Schoch, C. L., Arnold, A. E., Gueidan, C., Tripp, E., Yahr, R., Robertson, C., and Lutzoni, F.: New insights into classification and evolution of the Lecanoromycetes (Pezizomycotina, Ascomycota) from phylogenetic analyses of three ribosomal RNA- and two protein-coding genes, Mycologia, 98, 1088-1103, doi:10.3852/mycologia.98.6.1088, 2007.

Moore, D., Robson, G. D., and Trinci, A. P. J.: 21st Century Guidebook to Fungi, Cambridge University Press, 41-82, 2011.

Morgan, J. L., Darling, A. E., and Eisen, J. A.: Metagenomic sequencing of an in vitro-simulated microbial community, PLoS One, 5, e10209, doi:10.1371/journal.pone.0010209, 2010.

Morris, C. E., Sands, D. C., Vinatzer, B. A., Glaux, C., Guilbaud, C., Buffière, A., Yan, S., Dominguez, H., and Thompson, B. M.: The life history of the plant pathogen Pseudomonas syringae is linked to the water cycle, ISME J., 2, 321-34, doi:10.1038/ismej.2007.113, 2008.

Morris, C. E., Sands, D. C., Vanneste, J. L., Montarry, J., Oakley, B., Guilbaud, C., and Glaux, C.: Inferring the evolutionary history of the plant pathogen Pseudomonas syringae from its biogeography in headwaters of rivers in North America, Europe, and New Zealand, MBio, 1, e0010710, doi:10.1128/mBio.00107-10, 2010.

Morris, C. E., Sands, D. C., Glaux, C., Samsatly, J., Asaad, S., Moukahel, A. R., Gonçalves, F. L. T., and Bigg, E. K.: Urediospores of rust fungi are ice nucleation active at $>-10^{\circ} \mathrm{C}$ and harbor ice nucleation active bacteria, Atmos. Chem. Phys., 13, 4223-4233, doi:10.5194/acp-13-4223-2013, 2013.

Oksanen, J., Blanchet, F. G., Kindt, R., Legendre, P., Minchin, P. R., O’Hara, R. B., Simpson, G. L., Solymos, P., Stevens, M. H. H., and Wagner, H.: vegan: Community Ecology Package, available at: http://cran.r-project.org/package=vegan (last access: 1 December 2013), 2013.

Onofri, S., Selbmann, L., Zucconi, L., and Pagano, S.: Antarctic microfungi as models for exobiology, Planet. Space Sci., 52, 229 237, doi:10.1016/j.pss.2003.08.019, 2004.

Pashley, C. H., Fairs, A., Free, R. C., and Wardlaw, A. J.: DNA analysis of outdoor air reveals a high degree of fungal diversity, temporal variability, and genera not seen by spore morphology, Fungal Biol., 116, 214-24, doi:10.1016/j.funbio.2011.11.004, 2012.

Peay, K. G., Baraloto, C., and Fine, P. V. A.: Strong coupling of plant and fungal community structure across western Amazonian rainforests, ISME J., 7, 1852-61, doi:10.1038/ismej.2013.66, 2013.

Penton, C. R., St Louis, D., Cole, J. R., Luo, Y., Wu, L., Schuur, E. A. G., Zhou, J., and Tiedje, J. M.: Fungal diversity in permafrost and tallgrass prairie soils under experimental warming conditions, Appl. Environ. Microbiol., 79, 7063-72, doi:10.1128/AEM.01702-13, 2013.

Penton, C. R., Gupta, V. V. S. R., Tiedje, J. M., Neate, S. M., OphelKeller, K., Gillings, M., Harvey, P., Pham, A., and Roget, D. K.: Fungal Community Structure in Disease Suppressive Soils Assessed by 28S LSU Gene Sequencing, PLoS One, 9, e93893, doi:10.1371/journal.pone.0093893, 2014.

Pöschl, U., Martin, S. T., Sinha, B., Chen, Q., Gunthe, S. S., Huffman, J. A., Borrmann, S., Farmer, D. K., Garland, R. M., Helas, G., Jimenez, J. L., King, S. M., Manzi, A., Mikhailov,
E., Pauliquevis, T., Petters, M. D., Prenni, A. J., Roldin, P., Rose, D., Schneider, J., Su, H., Zorn, S. R., Artaxo, P., and Andreae, M. O.: Rainforest aerosols as biogenic nuclei of clouds and precipitation in the Amazon, Science, 329, 1513-1516, doi:10.1126/science.1191056, 2010.

Pouleur, S. S., Richard, C., Martin, J. G., and Antoun, H.: Ice nucleation activity in Fusarium acuminatum and Fusarium avenaceum, Appl. Environ. Microbiol., 58, 2960-4, 1992.

Pringle, A.: Asthma and the diversity of fungal spores in air, PLoS Pathog, 9, e1003371, doi:10.1371/journal.ppat.1003371, 2013.

Prosser, J. I.: Molecular and functional diversity in soil micro-organisms, Plant Soil, 244, 9-17, doi:10.1023/A:1020208100281, 2002.

Pummer, B. G., Atanasova, L., Bauer, H., Bernardi, J., Druzhinina, I. S., Fröhlich-Nowoisky, J., and Grothe, H.: Spores of many common airborne fungi reveal no ice nucleation activity in oil immersion freezing experiments, Biogeosciences, 10, 80838091, doi:10.5194/bg-10-8083-2013, 2013.

Quast, C., Pruesse, E., Yilmaz, P., Gerken, J., Schweer, T., Yarza, P., Peplies, J., and Glöckner, F. O.: The SILVA ribosomal RNA gene database project: improved data processing and web-based tools, Nucleic Acids Res., 41, D590-D596, doi:10.1093/nar/gks1219, 2013.

R Core Team: R: A Language and Environment for Statistical Computing, available at: http://www.r-project.org, last access: 1 January 2014.

Rajala, T., Peltoniemi, M., Hantula, J., Mäkipää, R., and Pennanen, T.: RNA reveals a succession of active fungi during the decay of Norway spruce logs, Fungal Ecol., 4, 437-448, doi:10.1016/j.funeco.2011.05.005, 2011.

Richard, C., Martin, J.-G., and Pouleur, S.: Ice nucleation activity identified in some phytopathogenic Fusarium species, Phytoprotection, 77, 83-92, doi:10.7202/706104ar, 1996.

Schmieder, R. and Edwards, R.: Quality control and preprocessing of metagenomic datasets, Bioinformatics, 27, 863-864, doi:10.1093/bioinformatics/btr026, 2011.

Solhaug, K. A., Gauslaa, Y., Nybakken, L., and Bilger, W.: UVinduction of sun-screening pigments in lichens, New Phytol., 158, 91-100, doi:10.1046/j.1469-8137.2003.00708.x, 2003.

Sussman, A. S. and Douthit, H. A.: Dormancy in microbial spores, Annu. Rev. Plant Physiol., 24, 311-352, 1973.

Tedersoo, L., Bahram, M., Polme, S., Koljalg, U., Yorou, N. S., Wijesundera, R., Ruiz, L. V., Vasco-Palacios, A. M., Thu, P. Q., Suija, A., Smith, M. E., Sharp, C., Saluveer, E., Saitta, A., Rosas, M., Riit, T., Ratkowsky, D., Pritsch, K., Poldmaa, K., Piepenbring, M., Phosri, C., Peterson, M., Parts, K., Partel, K., Otsing, E., Nouhra, E., Njouonkou, A. L., Nilsson, R. H., Morgado, L. N., Mayor, J., May, T. W., Majuakim, L., Lodge, D. J., Lee, S S., Larsson, K.-H., Kohout, P., Hosaka, K., Hiiesalu, I., Henkel, T. W., Harend, H., Guo, L.-D., Greslebin, A., Grelet, G., Geml, J., Gates, G., Dunstan, W., Dunk, C., Drenkhan, R., Dearnaley, J., De Kesel, A., Dang, T., Chen, X., Buegger, F., Brearley, F. Q., Bonito, G., Anslan, S., Abell, S., and Abarenkov, K.: Global diversity and geography of soil fungi, Science, 346, 12566881256688, doi:10.1126/science.1256688, 2014.

Vaïtilingom, M., Deguillaume, L., Vinatier, V., Sancelme, M., Amato, P., Chaumerliac, N., and Delort, A.-M.: Potential impact of microbial activity on the oxidant capacity and organic car- 
bon budget in clouds, P. Natl. Acad. Sci. USA, 110, 559-64, doi:10.1073/pnas.1205743110, 2013.

Wickham, H.: ggplot2: elegant graphics for data analysis, Springer New York, 2009.

Woo, A. C., Brar, M. S., Chan, Y., Lau, M. C. Y. Y., Leung, F. C. C. C., Scott, J. A., Vrijmoed, L. L. P. P., ZawarReza, P., and Pointing, S. B.: Temporal variation in airborne microbial populations and microbially-derived allergens in a tropical urban landscape, Atmos. Environ., 74, 291-300, doi:10.1016/j.atmosenv.2013.03.047, 2013.

Yamamoto, N., Bibby, K., Qian, J., Hospodsky, D., Rismani-Yazdi, H., Nazaroff, W. W., and Peccia, J.: Particle-size distributions and seasonal diversity of allergenic and pathogenic fungi in outdoor air, ISME J., 6, 1801-1811, doi:10.1038/ismej.2012.30, 2012.
Yamamoto, N., Nazaroff, W. W., and Peccia, J.: Assessing the aerodynamic diameters of taxon-specific fungal bioaerosols by quantitative PCR and next-generation DNA sequencing, J. Aerosol Sci., 78, 1-10, doi:10.1016/j.jaerosci.2014.08.007, 2014.

Zhang, N., Castlebury, L. A., Miller, A. N., Huhndorf, S. M., Schoch, C. L., Seifert, K. A., Rossman, A. Y., Rogers, J. D., Kohlmeyer, J., Volkmann-Kohlmeyer, B., and Sung, G.H.: An overview of the systematics of the Sordariomycetes based on a four-gene phylogeny, Mycologia, 98, 1076-1087, doi:10.3852/mycologia.98.6.1076, 2007. 